\title{
Blood transfusion during cardiac surgery: massive transfusion coagulopathy
}

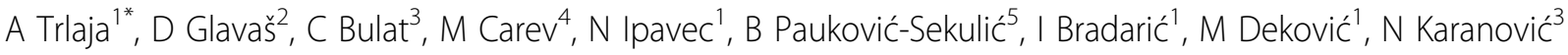 \\ From 23rd World Congress of the World Society of Cardio-Thoracic Surgeons \\ Split, Croatia. 12-15 September 2013
}

\section{Background}

Massive transfusion is usually defined as transfusion of more than 10 units of packed RBCs within 24h. Trigger for red cell transfusion in cardiac surgical patients is HGB $100 \mathrm{~g} / \mathrm{L}$ or HCT $0.30 \mathrm{~L} / \mathrm{L}$. We implemented control resuscitation with preemptive use of platelets and plasma in transfusion (1:1:1).

\section{Methods}

Total of 406 patients $(\mathrm{f} / \mathrm{m} \mathrm{N}=103 / 303)$ were studied in the ICU in 2011; 21 (5.17\%) males were observed,. HGB in OR prior to surgery was: $127.43 \mathrm{~g} / \mathrm{L}(\mathrm{SD} \pm 19.4$; range 85-165; median 129g/L). Patients were divided into two groups, according to the quantity of RBCs received. Group $1(\mathrm{~N}=15)$ received 5-9 units RBCs; group 2 $(\mathrm{N}=6)$ received $\geq 10$ units RBCs. EuroSCORE II was used for operation risk calculation. Patients abode 6.9 days $( \pm 7.97)$ in ICU. LVEF was $61.1 \pm 11.06 \%$. The consumption of RBCs, platelet concentrates (PCs), and fresh frozen plasma (FFP) within $24 \mathrm{~h}$ was calculated. In all these cases CBC, PT, aPTT and INR were used to evaluate perioperative bleeding. Patients were monitored prior to surgery and for the first $24 \mathrm{~h}$ of transfusion of blood components for creatinine, $\mathrm{pH}, \mathrm{Ca}++$, troponin I. Data are presented as median and IQR; mean and standard deviation, $\mathrm{P}<0.05$ was considered statistically significant.

\section{Results}

GROUP 1: (before/after) blood transfusion: PLT $171.47 \times 109 / \mathrm{L}( \pm 56.69) /$ PLT $139.53 \times 109 / \mathrm{L}( \pm 44.86)$; $\mathrm{P}=0.02$. PV 0.85(0.62-0.97) / 0.94(0.31-1.113); aPTT 30 (26-36) / 30 (26-120); aPTT R 1.04(0,91-1.18) / 1.05 (0.91-1.27). GROUP 2:PLT 156.67x109 L $( \pm 76.26) /$ PLT 119.67x109 ( \pm 62.44$) ; \mathrm{P}=0.04$. PV 0.78(53-1.09) / 0.94 (0.34-1.00); aPTT 32(25-49) / 35.5 (27-50); aPTT R 1.10 (0.86-1.70) / 1.23(0.93-1.71). Patients who were massively transfused received: RBC $10.5(\mathrm{SD} \pm 3.93 ; \mathrm{r}: 10-20)$ units, FFP 11(SD \pm 5.42 ; r:5-21) units, $\mathrm{PCs} 10(\mathrm{SD} \pm 5.11$; r:7-20) units.

\section{Conclusion}

With this protocol we prevent bleeding following massive transfusion that can occure due to hypothermia, dilutional coagulopathy, platelet dysfunction, fibrinolysis, and hypofibrinogenemia.

\section{Authors' details}

'Department of Transfusion, University Hospital Center Split, Split, Croatia. ${ }^{2}$ Department of Internal Medicine, University Hospital Center Split, Split, Croatia. ${ }^{3}$ Department of Cardiothoracic Surgery, University Hospital Center Split, Split, Croatia. ${ }^{4}$ Department of Anestesiology, Resuscitation and Intensive Care, University Hospital Center Split, Split, Croatia. ${ }^{5}$ Haematology Laboratory, University Hospital Split, Split, Croatia.

Published: 11 September 2013

doi:10.1186/1749-8090-8-S1-P110

Cite this article as: Trlaja et al.: Blood transfusion during cardiac surgery: massive transfusion coagulopathy. Journal of Cardiothoracic Surgery 2013 8(Suppl 1):P110.

* Correspondence: anuska.trlaja@st.t-com.hr

'Department of Transfusion, University Hospital Center Split, Split, Croatia

Full list of author information is available at the end of the article

(c) 2013 Trlaja et al; licensee BioMed Central Ltd. This is an Open Access article distributed under the terms of the Creative Commons 